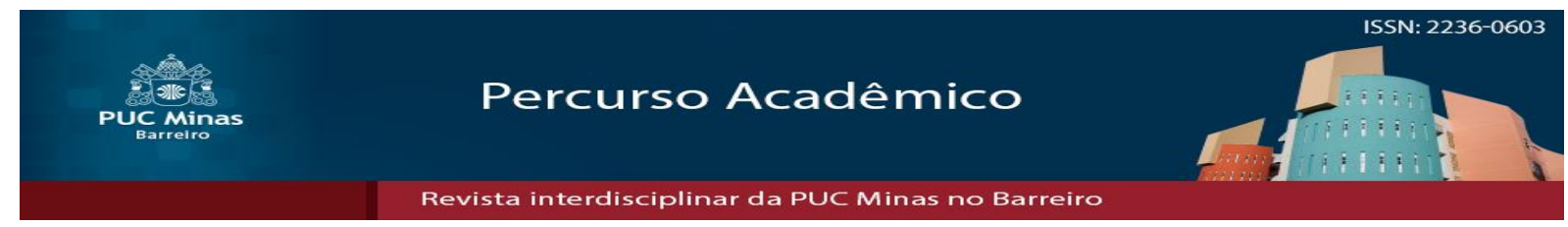

Artigo/DOSSIÊ TEMÁTICO

Licença Creative Commons Attribution 4.0 International license

\title{
Estudo sobre a aplicabilidade da metodologia dmaic no setor de protótipos de uma empresa automobilística
}

\section{Study on the applicability of the dmaic methodology in the prototype sector of an automobile company}

\begin{abstract}
RESUMO
O presente trabalho buscou analisar a aplicabilidade da metodologia DMAIC no processo de aquisição de matéria prima para a construção de peças protótipos para resolução do problema de atraso na entrega das mesmas. A abordagem metodológica utilizada tem base descritiva, qualitativa e exploratória. A aplicação foi realizada na forma de estudo de caso no setor de protótipos de uma montadora de veículos da região metropolitana de Belo Horizonte. O setor de protótipos é responsável pela construção de veículos que são um produto de trabalho na fase de testes e/ou planejamento de um projeto. Os resultados indicaram que a aplicação do método DMAIC a partir da utilização de ferramentas da qualidade, permitirá uma possível redução no atraso de entrega das peças do setor de protótipos.
\end{abstract}

Palavras - chave: DMAIC; Protótipo; Qualidade; Atraso de Entrega; Peças Automobilísticas.

\begin{abstract}
This work seeks to analyze the applicability of the DMAIC methodology in the process of acquiring raw material for the construction of prototype parts to solve the problem of delay in their delivery. The methodological approach used is descriptive, qualitative and exploratory based. The study was carried out analyzing the Prototypes sector inside a major automaker located on the metropolitan region of Belo Horizonte. The prototype sector is responsible for the construction of vehicles that are a product of work in the testing and/or planning phase of a project. The results indicated that the application of the DMAIC method from the use of quality tools will allow a possible reduction in the delivery delay of parts in the prototype sector.
\end{abstract}

Keywords: DMAIC; Prototype; Quality; Delivery Delay; Automotive Parts.

\footnotetext{
${ }^{1}$ Graduando em Engenharia de Produção pela Pontifícia Universidade Católica de Minas Gerais (PUC Minas). Brasil. E-mail: leandrovinte@gmail.com.

${ }^{2}$ Graduando em Engenharia de Produção pela Pontifícia Universidade Católica de Minas Gerais (PUC Minas). Brasil. E-mail: talyta.ferreira@sga.pucminas.br.

${ }^{3}$ Doutor em Engenharia Mecânica pela Universidade Federal de Minas Gerais, mestrado em Engenharia de Produção pela Universidade Federal de Santa Catarina. Possui graduação em Matemática pelo Centro Universitário Newton Paiva. Atualmente é sócio diretor da Melo Reis Consultoria e Treinamento Ltda, professor convidado da Fundação Dom Cabral, coordenador do curso de graduação em Engenharia de Produção da PUC Minas unidade Praça da Liberdade, e Diretor Administrativo Financeiro do Colégio Logosófico unidade Funcionários. Brasil. E-mail: roberts@pucminas.br.
} 


\section{INTRODUÇÃO}

As decisões estratégicas das organizações, visando atender os requisitos dos clientes do segmento da empresa de forma melhor ou igual à concorrência, é um fato de sucesso de qualquer negócio. Para atingir tal resultado, é fundamental o desdobramento de ações para o nível de gestão de operações da produção (CARPINETTI, 2016). Assim, o uso de ferramentas da qualidade que auxiliam a gestão dos processos, indicam pontos de atuações e propõem melhorias, tornaram-se essenciais para as organizações atingirem desenvolvimento e sobrevivência no mercado.

As indústrias, especialmente do setor automobilístico, hoje procuram aperfeiçoar a gestão da qualidade contribuindo para a melhoria da competitividade dos negócios frente à concorrência, visto que estão inseridas em um ambiente altamente competitivo (CARPINETTI, 2016).

Em entrevista para o jornal Estado de Minas (setembro/2019), Mauro Correia, presidente da montadora CAOA, afirma que "Quando olhamos a parte de veículos, automóveis e comerciais leves, o crescimento acumulado de janeiro a julho está em torno de 11\%. A estimativa para este ano, para uma indústria que, em 2018 produziu 2,5 milhões de unidades, é de 2,9 milhões. O que é positivo nisso, quando você vê o crescimento da indústria automobilística, é que a base de suprimentos no Brasil também é muito grande. O setor no país é muito robusto. Isso faz com que a economia gire em uma cadeia produtiva grande."

De acordo com a matéria publicada pelo Ministério da Economia (2019), hoje o mercado automotivo tem importante impacto sobre o nível de atividade da indústria de transformação, sendo que o crescimento da produção automotiva pode, por meio da sua cadeia de fornecimento, impulsionar o crescimento de vários outros setores da indústria que obtém um material e o transforma em um produto tangível, na maior parte dos casos. Tal cadeia de fornecimento é composta não apenas pelas montadoras, mas também por uma enorme gama de fornecedores diretos e indiretos, além das empresas responsáveis pelas vendas e distribuição dos veículos. A integração harmônica dos envolvidos impacta significativamente na entrega de peças com alta resistência e durabilidade (respeitando prazo e escopo), qualidades fundamentais na indústria automobilística. 
Para obter uma melhoria da qualidade e mantê-la estável, uma das análises a ser realizada é a parte interna do processo produtivo, para individualizar as causas na origem do processo e eliminá-las, não investindo somente nos controles e tomadas de decisão, mas também colocar as condições para que não haja repetição da causa original. Segundo a definição de Ishikawa, (1993) apud Werkema, (2012), praticar um bom controle da qualidade é desenvolver, projetar, produzir e comercializar um produto de qualidade que seja mais econômico útil e sempre satisfatório para o consumidor.

Da mesma forma que desenvolver um produto com qualidade, é importante controlar o processo que resulta na condução de uma produção ou na realização de um serviço mais eficiente, dinâmico e preciso (CAMPOS, 2014).

Dentro dessa perspectiva, o Seis Sigma é uma estratégia gerencial e disciplinada, reconhecida mundialmente. A base fundamental por trás do Seis Sigma, foi a ideia da utilização de técnicas estatísticas para prever comportamentos e melhorar os processos, desenvolvida por Walter A. Shewhart (PANDE, 2004).

O Seis Sigma pode ser entendido como uma estratégia de sucesso. É impulsionado principalmente por um desejo, pela compreensão das necessidades dos clientes, sejam eles internos, externos ou até mesmo do cliente final, baseado em fatos, dados e análises estatísticas e melhorias com o intuito de dar excelência nos processos do negócio.

Segundo Werkema (2012), no Seis Sigma há um método utilizado pelas instituições com o objetivo de trazer maior impacto e desenvolvimento ao projeto para atingir as metas estratégicas, conquistar mercados e melhorar a produtividade.

Tal método, denominado DMAIC, possui ênfase explícita a alguns elementos importantes no processo produtivo, como coletar e compreender as necessidades do cliente; controle estatístico do processo e confiabilidade dos resultados; e análise de quanto um projeto agregou valor à empresa em termos financeiros (WERKEMA, 2012, p.13).

O ambiente a ser estudado se dá na projeção e produção de automóveis, caminhões, tratores, máquinas agrícolas, motores, transmissões, peças fundidas, autopeças e sistemas de automação industrial, entre outros. No setor de automóveis, a empresa objeto de análise neste estudo, desenvolve suas atividades industriais e de serviços por meio de sociedades localizadas em 50 países e mantém relações comerciais com clientes em mais de 190 países. 
Estudo sobre a aplicabilidade da metodologia dmaic no setor de protótipos de uma empresa automobilística

Assim, o presente trabalho buscou-se analisar a aplicabilidade da metodologia DMAIC no setor de protótipo de uma fabricante de autopeças localizada na região metropolitana de Belo Horizonte. O setor de protótipos é responsável pela construção de veículos que são um produto de trabalho na fase de testes e/ou planejamento de um projeto.

Neste contexto, o processo de aquisição de matéria prima que serão utilizadas para construir as peças protótipos, envolve diferentes setores e pessoas, onde cada decisão dos responsáveis envolvidos pode trazer consequências decisivas para o resultado da qualidade final da peça, atraso nos prazos de entrega e consequentemente do projeto em que nele se encontra, e também falsos resultados nos indicadores de testes realizados na peça e no veículo protótipo.

Por meio da aplicação da metodologia DMAIC, buscou-se a melhoria do processo de aquisição de matéria prima para construção de autopeças, envolvendo melhor comunicação entre a cadeia de fornecimento e distribuição, aumentando a produtividade e a precisão dos resultados e reduzindo retrabalhos.

\section{REFERENCIAL BIBLIOGRÁFICO}

\subsection{Qualidades e o gerenciamento de processos}

Para se posicionar como líder no mercado em função das suas potencialidades é fundamental que as empresas olhem para os aspectos externos (concorrência) e internos (processos produtivos) a que estão expostas. O planejamento estratégico de um processo, seja ele de bens ou serviços, é uma considerável etapa para a alavancagem no crescimento das empresas e apresenta-se como uma vantagem competitiva no mercado em que atuam (BESANKO, 2012, p.55).

Assim, deve-se analisar o fluxo de tarefas que está diretamente ligado à qualidade final do produto, já que a forma como o processo se dá interfere em como este produto irá satisfazer as expectativas do cliente. Neste contexto, um problema presente no processo de fabricação das autopeças protótipos, corresponde ao atraso de entrega das mesmas.

Sendo assim, é considerável a gestão da qualidade ser aplicada como estratégia competitiva para atingir as metas, objetivos e planos das instituições, e conter os problemas de produção. Mas o que seria de fato "qualidade"? Tal conceito surgiu ainda 
quando os sistemas de produção eram estritamente artesanais com a ideia apenas de perfeição técnica de um produto oferecido e o próprio produtor era quem coletava a matéria prima, produzia e inspecionava manualmente.

\begin{abstract}
Após as Revoluções Industriais e com o advento de teorias de Administração Científica da Produção, a qualidade é vista hoje como adequação do produto ao uso do consumidor e satisfação das suas necessidades, baseados predominantemente em sistemas de produção em massa e com uma inspeção e manutenção mais rigorosa (CARPINETTI, 2016, p.18).
\end{abstract}

Segundo Carpinetti (2016), a busca por atender as exigências dos clientes, reorientou as organizações em reduzir os problemas e aperfeiçoar os produtos através de duas abordagens: melhoria contínua e melhoria radical. A melhoria contínua, como o próprio nome sugere, está ligada a ciclos de melhoria, a processos de constante exame que serão complementados com ações de contenção e desempenho de processo. Assim, a melhoria contínua é abastecida por métodos com etapas bem definidas que visam sistematizar o processo tornando-o automatizado.

\title{
1.2 Manufatura Enxuta
}

Tratando-se desse contexto onde a gestão da qualidade tem significativa parcela de valor dentro das organizações e visando sempre atender da maneira mais correta, segura, e no tempo certo às necessidades dos clientes, as estratégias baseadas em excelência operacional que se destinam a melhorar os indicadores da qualidade, custos operacionais e tempo de entrega são essenciais para tal objetivo.

Segundo Tubino (2015), tratando de desperdício como tudo o que é gerado pela empresa que consome recursos e não agrega valor, o estudo em como evitá-los se faz necessário, o que é tratado como base no sistema Lean Manufacturing (Manufatura Enxuta).

Na busca pela utilização mínima dos recursos disponíveis, e da identificação dos desperdícios, a filosofia Lean Manufacturing (Manufatura Enxuta) visa aumentar as atividades que somem valor, não apenas para a empresa $\mathrm{e}$ os colaboradores, mas principalmente para os clientes. Alinhados da melhor maneira possível essas atividades, entendida como "Fluxo de Valor", e de forma contínua, sempre que solicitada pelo cliente, devem ser executadas da maneira mais eficaz, evitando possíveis interrupções na busca da perfeição. Para que assim, consiga melhorias nos indicadores de qualidade, de custo operacional e entrega (TUBINO, 2015, p.23-24). 


\subsection{Seis Sigma}

Seis Sigma é entendido como uma estratégia gerencial que enriquece a qualidade por meio da melhoria contínua, seja ela dos processos compreendidos à produção de um produto ou serviços. Considera todos os setores e atividades de relevância de um negócio com a intenção de agilizar o aperfeiçoamento em processos, serviços e nos produtos (ROTONDARO, 2002, p. 18).

O objetivo do Seis Sigma é buscar a excelência, chegar o mais próximo possível a "zero defeito", defendendo uma filosofia de melhoria contínua dos processos e da redução de variabilidade, relacionando o projeto, fabricação, qualidade final, a entrega do produto e a satisfação dos consumidores (ROTONDARO, 2002, p. 18).

O Seis Sigma é aplicável em processos técnicos e não técnicos segundo Rotondaro (2002). Em um processo não técnico, que é foco deste trabalho, não há considerável clareza no sentido de fluxo. Assim, a visualização e entendimento torna-se custosa.

Processos administrativos são considerados não técnicos e de serviços, como por exemplo a aquisição de matéria prima para a construção de aquisição de peças em uma indústria automobilística, o qual demanda análises e burocracias. Conforme Slack (1999), tratar esses tipos de serviços como processos, ajuda a entendê-los melhor e conhecer suas características. Para assim aprimorá-los e controlá-los, diminuindo erros, falhas, tempo de execução e aumentando a satisfação do cliente.

\subsubsection{DMAIC}

O DMAIC é um dos elementos do Seis Sigma e é usado em sua maioria em projetos que desejam alcançar melhorias nos processos em questão, possibilitando um bom direcionamento para as fases de projetos que estão por vir. De acordo com Carpinetti (2016), existem alguns casos em que a necessidade de redução de custos é mais preocupante do que em outros. É o caso, por exemplo, da indústria automobilística, em que a redução de desperdícios e valores de não qualidade advindos dos retrabalhos e refugos da produção gera maior impacto no progresso dos resultados financeiros pelo fato de ser uma produção em série que produz em grandes quantidades. Nesse aspecto, a cultura de implantar metodologias de melhoria contínua, tais como 


\section{Leandro Brant Vitoriano Vinte, Talyta Ferreira de Oliveira e}

Roberts Vinicius de Melo Reis

DMAIC, proporciona resultados benéficos propagando e consolidando a qualidade da produção.

As contribuições do método DMAIC são inúmeras, dentre elas propiciar uma análise sistêmica dos problemas de não qualidade e suas causas, promovendo uma melhoria do processo através de cinco etapas bem definidas que compõem o DMAIC (CARPINETTI, 2016):

- Etapa D (Define): etapa de iniciação do projeto, no qual são definidos os processos mais críticos e objetivos para se trabalhar e alcançar as metas.

Nesta primeira etapa do DMAIC, o propósito de estudo e a meta do projeto devem ser definidos claramente, e pontos principais a respeito do problema precisam ser conhecidos, como por exemplo: quais as principais características para garantir a qualidade do produto, quem afeta e/ou será afetado pelo problema, quais os clientes, os processos relacionados à realização das atividades e ao problema e qual o impacto financeiro ou ganho em tempo e produtividade.

- Etapa M (Measure): É nessa etapa que o planejamento ganha maior vigor, onde é feita a coleta dos dados que auxiliarão em atender as necessidades e expectativas do cliente e do processo.

Na segunda etapa do DMAIC, o problema a ser estudado terá de ser lapidado ou ressaltado. Por meio das atividades, e análises que estão inseridas nessa etapa, o problema pode ser fracionado em problemas menores ou mais específicos, consequentemente mais fácil de resolver.

Assim como na primeira etapa, algumas questões devem estar bem claras e de fácil entendimento, como quais serão os dados de medição necessários, e quais são os principais focos do problema a ser resolvido, sem que haja interferência na rotina da produção.

- Etapa A (Analyze): Nesta etapa a execução dita a rotina das atividades, as análises de desempenho do processo e o levantamento dos problemas tomam forma. $\mathrm{O}$ objetivo é identificar as principais causas dos problemas. Ademais, considera-se nesta etapa ações a serem tomadas, baseadas em um plano detalhado e com responsáveis direcionados.

Nesta terceira etapa do DMAIC, as causas dos problemas deverão ser definidas e correlacionadas a cada uma das metas que foram definidas na segunda etapa. Para melhor entendimento das causas fundamentais do problema, Werkema (2012) diz que é necessário realizar dois tipos de análise. Primeiramente o exame do processo 
gerador do problema (Process Door), indicado para se obter um melhor entendimento do fluxo de atividades e assim encontrar oportunidades de melhoria.

- Etapa I (Improve): Entrando na parte de finalização e concluindo as análises e levantamento de ações tomadas na etapa anterior, nessa etapa a execução das ações de melhoria devem ser bem planejadas.

Após a implementação das ações e possíveis ajustes, a equipe deve avaliar se o problema solucionado tivera força e potencial para alcançar as metas antes definidas. Werkema (2012) diz que se essas metas não forem alcançadas, deve-se retomar a segunda etapa do DMAIC, para melhor entendimento e análise do processo, ou até mesmo elaborar um novo projeto.

- Etapa C (Control): Após a conclusão de todas etapas e ações pontuais, o controle das operações e do desempenho dos processos é fundamental para a melhora ser efetiva.

A forma de condução das atividades deve ser levantada para que as pessoas envolvidas tenham ciência e possam refletir sobre, e também para que os pontos que não foram abordados no projeto possam ser levantados.

De acordo com Werkema (2012), diversas ferramentas também são empregadas de maneira adaptada nos estágios do DMAIC, que se transforma então em uma poderosa técnica movida pelos dados e pela utilização de ferramentas estatísticas para alcançarem as metas estratégicas almejadas pelas empresas.

Prezando por garantir qualidade ao produto e/ou serviço final, cada etapa do DMAIC gera consideráveis verificações dos dados, resoluções concretas e manutenção ao longo do processo, a partir da integração de ferramentas da qualidade (WERKEMA, 2012). Segundo Cleto; Quinteiro, (2011) apud Oliveira; Silva, (2017), a transição entre as etapas do DMAIC devem ser inspecionadas por fiscais capacitados, pois assim os gestores e coordenadores do projeto obtém uma visão externa da situação e pontos de melhoria podem ser levantados, tornando-se uma prática que contribui positivamente para o sucesso da organização.

\subsection{Ferramentas da Qualidade}

A metodologia DMAIC é marcada pela utilização de diversas ferramentas da qualidade de forma ordenada, que resultam de maneira simples e objetiva as informações que são buscadas e necessárias em cada fase do projeto. Na sequência, 
serão apresentadas as ferramentas da qualidade utilizadas e as respectivas definições, julgadas como necessárias na execução do projeto.

\section{a) Etapa D (Define)}

\section{a.1) Project Charter}

De acordo com Werkema (2012), essa ferramenta se dá como relevante na fase de definição do projeto e representa uma espécie de contrato firmado entre as partes envolvidas no projeto, a equipe responsável pela execução do projeto e os gestores da empresa.

Além disso, a ferramenta tem como objetivo manter a equipe alinhada com o foco do projeto, apresentar o que é esperado em relação à equipe, formalizar as principais definições do projeto através de cronogramas, escopo e meta.

\section{a.2) SIPOC}

Uma ferramenta também utilizada em atividades relacionadas ao Seis Sigma é o SIPOC, resultante das iniciais em inglês, de cinco aspectos presentes na ferramenta, são eles: fornecedores (Suppliers), insumos (Inputs), processo (Process), produtos (Outputs) e consumidores (Customers) (WERKEMA, 2012).

Por meio desta ferramenta, como explicado por Werkema (2012), é possível esclarecer melhor as etapas do processo, de forma visual e padronizada, definindo e formalizando fatores que podem impactar diretamente na execução e resultado do trabalho.

\section{b) Etapa M (Measure)}

\section{b.1) Estratificação}

A estratificação é uma ferramenta de qualidade que consiste em uma divisão de um grupo em diversos subgrupos com características distintas entre si. A estratificação permite analisar os dados separadamente por classe de subgrupo para descobrir detalhadamente as causas de um problema (CARPINETTI, 2016, p.28). 
Estudo sobre a aplicabilidade da metodologia dmaic no setor de protótipos de uma

\section{empresa automobilística}

Com a estratificação dos dados ou do problema, consegue-se perceber como a variação de cada um desses fatores estabelecidos nos subgrupos interferem no resultado do processo ou do problema investigado. Além disso, ordena-se o que está sendo analisado facilitando o entendimento a todos que tem acesso a ferramenta (CARPINETTI, 2016, p.26).

\section{b.2) Diagrama de Pareto}

O Princípio de Pareto desenvolvido por Vilfredo Pareto, apresenta o conceito de que, a maior parte das consequências decorrentes dos problemas, são resultados de poucas, porém vitais causas.

O Diagrama de Pareto dispõe a informação de forma a tornar a visualização evidente e de fácil compreensão, ordenando pela importância do problema as causas de perdas. Porém, isso não quer dizer que todos os problemas devem ser solucionados, mas sim que alguns desses problemas precisam ser resolvidos com maior prioridade (CARPINETTI, 2016, p.31).

\section{c) Etapa A (Analyze)}

\section{c.1) Fluxograma}

O Fluxograma é mais uma ferramenta de qualidade, que de acordo com Barros e Bonafini (2014) é utilizada na representação de uma sequência e interação de atividades realizadas no processo por meio de simbologias gráficas, que proporcionam um melhor entendimento a partir da visualização do funcionamento do processo estudado. Com essa ferramenta é possível aumentar a produtividade dos trabalhadores, pois esclarece melhor o fluxo de trabalho e dá espaço para realizar melhorias.

Além disso, a utilização dessa ferramenta mostra-se valiosa, pois apresenta os passos a serem seguidos na realização do trabalho, cria normas padrão para a execução dos processos, auxilia na busca das falhas e facilita a consulta em casos de objeções sobre o processo (BARROS; BONAFINI, 2014, p.9). 


\section{c.2) Diagrama de Causa e Efeito}

Criado por Kaoru Ishikawa, o Diagrama de Causa e Efeito, também conhecido como "Diagrama de Espinha de Peixe" ou Diagrama de Ishikawa, considera todos os aspectos e causas raízes que levam a ocorrência de um problema.

De acordo com Carpinetti (2016), o Diagrama de Causa e Efeito apresenta a relação existente entre o resultado indesejado de um processo (efeito) e os demais fatores (causas) que contribuem para que esse problema tenha ocorrido.

A aplicação desta ferramenta mostra-se adequada para ampliar o campo de visão das possíveis causas de um problema, e também para gerar melhorias nos processos.

\section{d) Etapa I (Improve)}

\section{d.1) $5 \mathrm{~W} 2 \mathrm{H}$}

A ferramenta da qualidade $5 \mathrm{~W} 2 \mathrm{H}$ mostra-se eficaz quando se depara com problemas ou necessidades onde não pode-se tomar ações sem antes realizar uma análise da situação. Precisa-se identificar primeiro os meios para depois resolvê-los.

Como explicitado por Werkema (2012), o 5W2H tem como objetivo definir, de acordo com a estratégia, os seguintes itens:

-What: o que será feito (etapas);

- When: quando será feito (tempo);

-Who: por quem será feito (responsável);

- Where: onde será feito (local);

- Why: por que será feito (justificativa);

- How: como será feito (método);

- How much: quanto custará fazer (custo);

\section{d.2) Stakeholders Analysis}

De acordo com Werkema (2012), a ferramenta Stakeholders Analysis tem como principal objetivo apresentar informações referentes aos Stakeholders, que são o público estratégico ou os indivíduos e organizações impactados pelas ações da empresa. 
Estudo sobre a aplicabilidade da metodologia dmaic no setor de protótipos de uma

\section{empresa automobilística}

As informações apresentadas pela ferramenta, consistem em relações interpessoais dos Stakeholders, os níveis de comprometimento atuais e os níveis necessários para que as implementações das soluções prioritárias de cada um sejam bem executadas.

\section{METODOLOGIA}

O presente trabalho de natureza qualitativa, descritiva e exploratória é um estudo de caso com o objetivo de levantar, por meio do DMAIC, os elementos relacionados ao processo de aquisição de matéria prima que ocasiona o atraso na entrega das peças do setor de protótipos em uma montadora de veículos e assim, melhorá-lo.

Yin (2014) descreve pesquisa qualitativa como um estudo que tem por objetivo explicar o desempenho dos papéis de cada indivíduo em situações cotidianas, representado pelas diferentes visões e perspectivas dos fatos da vida real que vivenciam, através de conceitos existentes ou emergentes.

\footnotetext{
Outro conceito importante também descrito por Yin (2015) refere-se ao estudo de caso, definido como um método de pesquisa que investiga uma situação dentro de seu contexto da vida real, especialmente quando não há total clareza entre o "caso" a ser estudado e as circunstância em que ele ocorre. A elaboração do estudo de caso torna-se relevante quando as questões principais de um fenômeno são "como?" e "porquê?" bem como a falta de controle sobre os eventos comportamentais do fenômeno. Esse método de pesquisa possui mais variáveis de interesse do que pontos de dados (YIN, 2015, p. 6-7).
}

Como instrumento de coleta de dados, foram realizadas 17 entrevistas via Google Forms Online, com o objetivo de captar os conceitos a respeito do termo "qualidade" e as considerações gerais sobre as autopeças na visão das pessoas que participam ativamente do processo analisado. As entrevistas têm tipologia estruturada a qual fornecem inferências causais percebidas trazendo enfoque diretamente ao tópico do estudo caso (TURRIONI; MELLO, 2012, p. 10).

Ademais, recorreu-se à análise de documentos eletrônicos como e-mails e planilhas pelo histórico de projetos da empresa para verificar quais foram as adversidades ocorridas nas peças devido a problemas com matéria prima. "Desse modo, pôde-se obter uma análise holística da empresa estudo de caso" (CRESWELL, 2014, p.23). 


\section{Roberts Vinicius de Melo Reis}

Tais escolhas ficam claras quando Creswell afirma que "O critério de amostragem funciona bem quando todos os indivíduos estudados representam as pessoas que experimentaram o fenômeno" (CRESWELL, 2014, p. 124).

\section{DESENVOLVIMENTO}

Para dar início à análise do processo, decidiu-se entrevistar os stakeholders, sendo pelo menos uma pessoa de cada setor (demonstrados na Figura 1). Optou-se por entrevistar esses profissionais, pois participam diretamente do processo produtivo das peças automobilísticas e são vozes ativas na aquisição de materiais para produção das mesmas.

Figura 1: Relação de stakeholders.

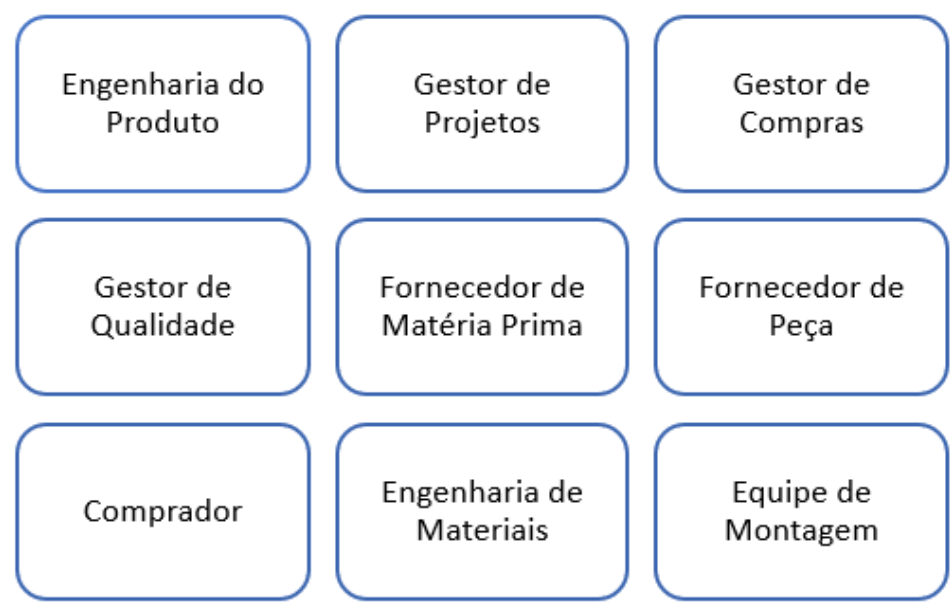

Fonte: Elaborada pelos autores, (2019).

As entrevistas, realizadas no período de janeiro/2020 a fevereiro/2020, são compostas por um roteiro padronizado de 12 perguntas (demonstradas no Anexo A) a fim de obter respostas para os mesmos questionamentos que permitam uma comparação das diferentes interferências que os entrevistados causam na aquisição de matéria prima das peças e quais os problemas enfrentados pelos mesmos. O objetivo era também conhecer as diversas visões e perspectivas dos atores do processo sobre a qualidade esperada da peça produzida com o material especificado. Assim, chegaria a um conceito de qualidade comum, sendo norte para levantar os elementos do processo de aquisição de matéria prima que é fator decisório para tal fim e assim, melhorá-lo.

Nas entrevistas foram avaliadas variáveis como, tempo de desenvolvimento e entrega da peça, peso na tomada de decisões, modos de falhas nos processos, influência 


\section{empresa automobilística}

da qualidade da matéria prima na satisfação dos clientes, bem como a importância da melhoria do processo. Os dados foram armazenados em planilha Excel e posteriormente inseridos em uma tabela específica para fazer a análise dos resultados, onde foram abordadas as variáveis citadas acima.

A partir da entrevista notou-se que as preocupações vivenciadas pelos stakeholders englobam em maioria no atraso de entrega das peças e resultados negativos nos testes, como demonstrados no Quadro 1. Esses problemas, segundo as respostas dos entrevistados (Quadro 1) estão ligados ao fato do dimensional e material da peça estarem fora do especificado, impossibilitando a realização de testes de qualidade e segurança que são necessários para aprovação do veículo no setor de protótipos da fábrica, além de comprometerem o cronograma estipulado pelos gestores de projeto.

Quadro 1: Amostra de respostas da entrevista estruturada.

\begin{tabular}{|c|c|c|c|}
\hline $\begin{array}{l}\text { Qual a sua função em } \\
\text { relaçäo ao processo } \\
\text { produtivo de peças } \\
\text { automobilisticas? }\end{array}$ & $\begin{array}{l}\text { Quais os problemas } \\
\text { recorrentes quando a peça não } \\
\text { possui a qualidade que } \\
\text { esperava? }\end{array}$ & $\begin{array}{l}\text { Qual sua opiniäo sobre a } \\
\text { importância da matéria prima no } \\
\text { processo produtivo das peças? }\end{array}$ & $\begin{array}{l}\text { Quais os problemas } \\
\text { ligados à matéria prima } \\
\text { das peças, que você } \\
\text { enfrenta em um projeto? }\end{array}$ \\
\hline $\begin{array}{l}\text { Project Chief, gestão do } \\
\text { projeto. }\end{array}$ & $\begin{array}{c}\text { Atraso no cronograma e } \\
\text { inconfiabilidade em testes } \\
\text { executados. }\end{array}$ & $\begin{array}{l}\text { Essencial. Como etapa inicial, não } \\
\text { há garantia do restante do } \\
\text { processo produtivo. }\end{array}$ & $\begin{array}{l}\text { Discordância de Material } \\
\text { solicitado e entregue, } \\
\text { comportamento diferente ao } \\
\text { visto em cálculo. }\end{array}$ \\
\hline $\begin{array}{c}\text { Analista de projetos focado } \\
\text { na gestão de compras para } \\
\text { peças prototipais }\end{array}$ & $\begin{array}{l}\text { Vários. No caso de peças } \\
\text { prototipais os principais são em } \\
\text { alguns casos o comprometimento } \\
\text { da segurança do piloto de testes } \\
\text { e o atraso na delibera dos } \\
\text { componentes testados, } \\
\text { ocasionando atraso no projeto } \\
\text { como um todo. }\end{array}$ & $\begin{array}{l}100 \% \text { importante. Sem a garantia } \\
\text { de uma matéria prima conforme } \\
\text { especificação técnica o Projeto } \\
\text { como um todo pode sofrer } \\
\text { impactos de tempo, custo, de } \\
\text { segurança com os colaboradores. }\end{array}$ & $\begin{array}{c}\text { Pças sem a capacidade de } \\
\text { suportar o que foi projetado } \\
\text { para executar. }\end{array}$ \\
\hline $\begin{array}{c}\text { Gestão da qualidade } \\
\text { acompanhando o processo } \\
\text { produtivo das peças e apoio } \\
\text { à aquisição de matéria prima }\end{array}$ & $\begin{array}{c}\text { Material incorreto, atraso na } \\
\text { entrega, anomalia de montagem } \\
\text { e dimensional. }\end{array}$ & $\begin{array}{l}\text { Total importância, pois impacta } \\
\text { nos testes em que a peça será } \\
\text { aplicada em relação às condições } \\
\text { de temperatura, tensão, etc. }\end{array}$ & $\begin{array}{l}\text { Dificuldade de aquisição, } \\
\text { indisponibilidade no } \\
\text { mercado. }\end{array}$ \\
\hline
\end{tabular}

Fonte: Elaborada pelos autores, (2020).

Outro parâmetro avaliado a partir das respostas da entrevista é a visão de qualidade dos stakeholders e qual a expectativa de qualidade da autopeça que os mesmos tinham. O Quadro 2 apresenta uma amostra das respostas da entrevista estruturada aplicada às partes envolvidas no processo. Notou-se que o produto final com qualidade esperado pela equipe deve atender às necessidades do cliente e as normas específicas de dimensional e matéria prima estipulados no início do projeto. 
Quadro 2: Amostra de respostas da entrevista estruturada.

\begin{tabular}{|c|c|c|}
\hline $\begin{array}{c}\text { Qual a sua função em } \\
\text { relação ao processo } \\
\text { produtivo de peças } \\
\text { automobilisticas? }\end{array}$ & $\begin{array}{c}\text { Para você, o que significa } \\
\text { "qualidade"? }\end{array}$ & $\begin{array}{c}\text { Qual sua expectativa em relação } \\
\text { à peça protótipo, ou seja, o que } \\
\text { espera de qualidade para ela? }\end{array}$ \\
\hline Gestor de Projetos & $\begin{array}{c}\text { Atender a necessidade / critérios } \\
\text { de uma demanda. }\end{array}$ & Atender as normas específicas. \\
\hline Comprador & $\begin{array}{c}\text { Entregas em conformidade com a a } \\
\text { necessidade do cliente e no } \\
\text { tempo certo. }\end{array}$ & $\begin{array}{c}\text { Que atenda a qualidade minima } \\
\text { para os testes aos quais será } \\
\text { destinada. }\end{array}$ \\
\hline $\begin{array}{c}\text { Validação dos materiais } \\
\text { metálicos utilizados. }\end{array}$ & $\begin{array}{c}\text { Atender os requisitos de } \\
\text { desempenho esperado. }\end{array}$ & $\begin{array}{c}\text { Que seja similar à qualidade do } \\
\text { produto normal produção. }\end{array}$ \\
\hline $\begin{array}{c}\text { Realizar programação de } \\
\text { aço nas usinas para } \\
\text { atendimento do processo } \\
\text { produtivo. }\end{array}$ & $\begin{array}{c}\text { Entregar o produto para o cliente } \\
\text { de forma que satisfaça a sua } \\
\text { necessidade com confiabilidade e } \\
\text { segurança. }\end{array}$ & $\begin{array}{c}\text { E fundamental para elaboração } \\
\text { dos novos modelos, verificando } \\
\text { aplicação do tipo de aço nas } \\
\text { peças, conformidade e segurança. }\end{array}$ \\
\hline
\end{tabular}

Fonte: Elaborada pelos autores, (2020).

Diante dessa situação, infere-se que perdas geradas pelo processo de aquisição de matéria prima não padronizado, podem gerar resultados não esperados diante dos parâmetros de satisfação, estes ligados ao dimensional e material da autopeça. Deste modo, a melhoria do processo através da metodologia DMAIC será realizada mediante as expectativas de qualidade das partes interessadas para as peças automobilísticas.

Paralelamente a isso, analisou-se os tipos de contato que os stakeholders possuem entre eles. A análise foi feita sob as respostas da entrevista via Google Forms Online por meio de gráfico de pizza disposto na figura 2. Os entrevistados que dizem possuir pouco contato (17,6\% pessoas) são aquelas ligadas ao fornecimento da peça e da matéria prima, empresas estas que se encontram fora da fábrica. Como o objetivo do trabalho é propor melhorias ao processo, o controle do mesmo é fundamental e para isso deve existir uma comunicação clara e formalizada em 100\% das atividades. 
Figura 2: Gráfico de pizza: tipo de contato entre stakeholders.

Qual sua relação com outros setores que fazem parte do processo produtivo das peças? 17 respostas

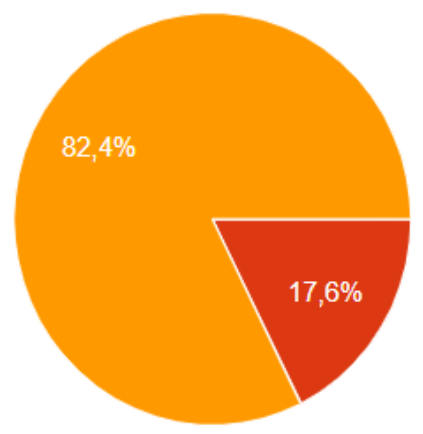

Fonte: Google Forms Online, (2020).

Ao fazer a análise das relações interpessoais com as funções exercidas de cada um do processo a partir da Figura 3 percebe-se que, as pessoas que possuem uma relação embaraçosa e/ou indiferente $(29,4 \%)$ são em maioria aquelas que possuem hábitos e poder de tomar decisões que impactam diretamente no processo de aquisição de matéria prima e construção da peça. Pelo fato de possuírem contato com maior parte das pessoas envolvidas no processo, essas decisões por sua vez, podem acabar gerando dúvidas e alguns conflitos de opiniões, mas que devem ser respeitados para que o processo de aquisição de material flua bem e no tempo certo.

O contato com os fornecedores de matéria prima, mostra-se de extrema importância para o funcionamento de toda a cadeia relacionada ao processo em que está sendo analisado. A comunicação correta e eficiente, assim como na equipe de colaboradores, também tem sua importância quando se diz respeito a cumprimento de prazos e especificações antes acordadas com aqueles fornecedores que estão distantes do projeto final da área envolvida.

As decisões de mudança acontecem por não cumprimento de prazo e especificação da peça (material e dimensional). O que está diretamente relacionado com os problemas que os envolvidos sofrem, pois os mesmos alegam que sofrem com problema de atraso da peça e falha nos testes relacionado com o material e dimensional da peça.

Em contrapartida, analisando o gestor de qualidade, que mantém contato direto com toda a cadeia de envolvidos e não tem a responsabilidade de tomar decisões no processo, faz que suas relações sejam harmônicas. Conclui-se que o grau de contato 


\section{Leandro Brant Vitoriano Vinte, Talyta Ferreira de Oliveira e}

Roberts Vinicius de Melo Reis

aliado ao poder de decisão é proporcional ao grau de relações embaraçosas no processo dificultando o andamento do processo.

Figura 3: Gráfico de pizza: tipo de relação entre stakeholders.

Como é sua relação com outros setores que fazem parte do processo produtivo das peças? 17 respostas

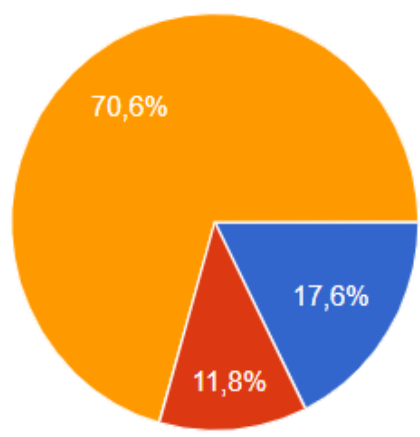

indiferente

relações embaraçosas

relações harmônicas

Fonte: Google Forms Online, (2020).

\subsection{Aplicação da Metodologia DMAIC}

Aplicou-se a metodologia DMAIC pelos pesquisadores do trabalho para levantar as causas das perdas do processo de aquisição de matéria prima para construção de autopeças com o objetivo de alcançar melhorias, possibilitando atividades mais eficazes e efetivas nos projetos atuais e futuros.

Para atingir tal objetivo, fez-se uso de ferramentas da qualidade integradas em cada etapa do DMAIC atreladas aos dados coletados na entrevista estruturada e documentos eletrônicos como e-mails, planilhas e relatórios de não conformidade disponibilizados pela empresa.

\subsubsection{Etapa D (Define)}

Para introduzir a aplicação do DMAIC e definir os passos iniciais do trabalho, elaborou-se o Project Charter (Figura 4) apresentando as expectativas das atividades a serem realizadas, respectivos responsáveis e datas, possíveis restrições e como serão elaboradas tais atividades, a fim de analisar o processo de aquisição de matéria prima. 
Estudo sobre a aplicabilidade da metodologia dmaic no setor de protótipos de uma

\section{empresa automobilística}

Figura 4: Project Charter do projeto

\begin{tabular}{|c|c|c|}
\hline \multicolumn{3}{|c|}{ Project Charter } \\
\hline Título do Projeto: & $\begin{array}{r}\text { Estudo Sobre A Aplicabilidade Da Metodologia Desaic do Problema: } \\
\text { Protótor De }\end{array}$ \\
\hline \multicolumn{3}{|c|}{ Objetivos do Projeto (Meta): } \\
\hline Atraso na entrega e não atendimento à testes de peças automobilisitcas devido a \\
indisponibilidade e não qualidade da matéria prima.
\end{tabular}

Fonte: Elaborada pelos autores, 2020.

Para definição da meta do trabalho consultou-se as respostas da entrevista estruturada via Google Forms Online e notou-se que as expectativas dos participantes eram diversas além de cada integrante do processo tomar decisões sem consultar e/ou comunicar os outros integrantes. Assim, estabeleceu-se como meta a melhoria do processo para reduzir o tempo de entrega das peças do projeto.

Na etapa inicial também utilizou-se o diagrama SIPOC, conforme demonstrado na Figura 5, para facilitar a visualização do escopo do projeto, descrevendo as partes envolvidas e suas responsabilidades, as entradas para realização das atividades e as entregas ao cliente final. 


\section{Leandro Brant Vitoriano Vinte, Talyta Ferreira de Oliveira e}

Roberts Vinicius de Melo Reis

Figura 5: Diagrama SIPOC do projeto

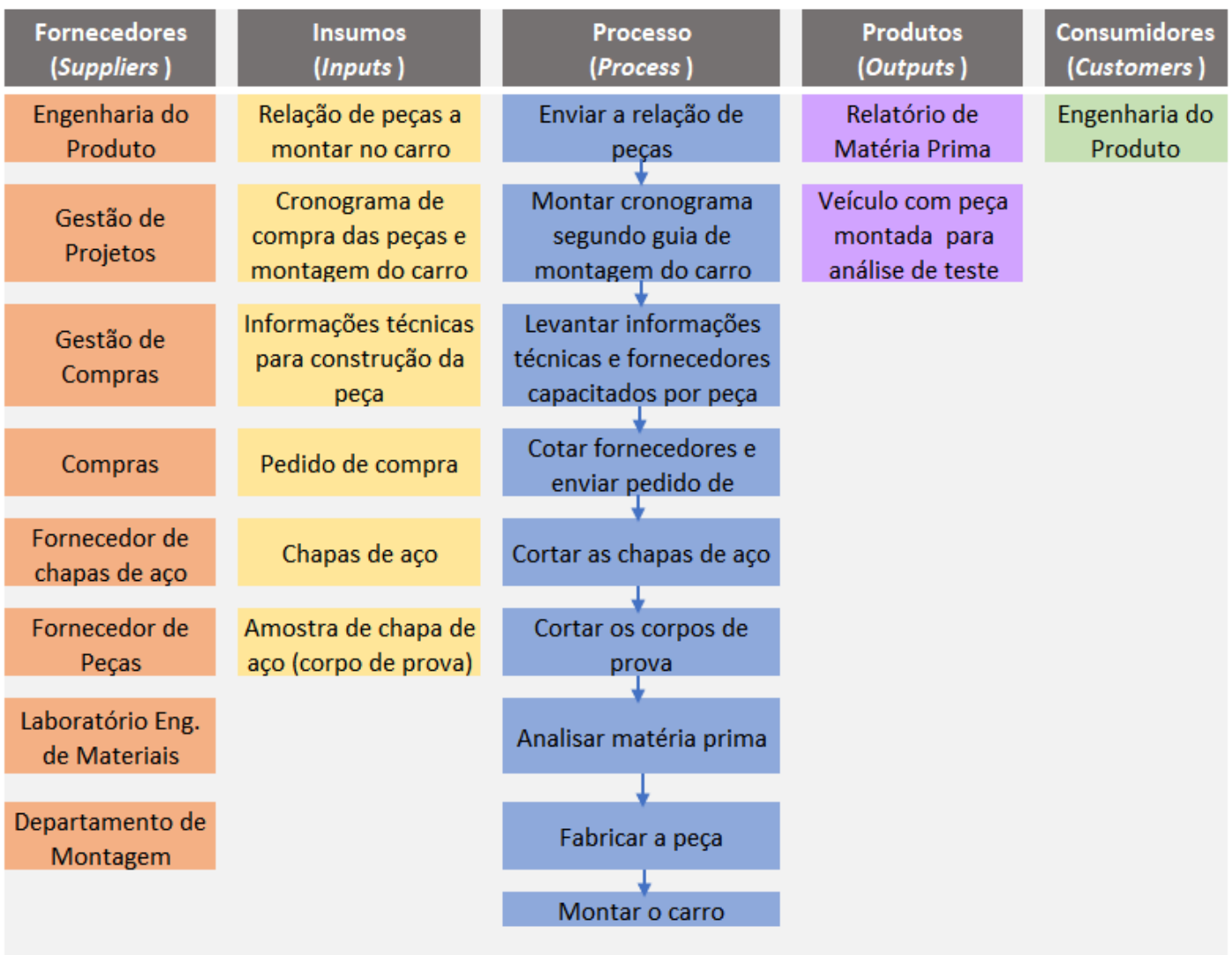

Fonte: Elaborada pelos autores, 2020.

\subsubsection{Etapa M (Measure)}

Finalizado a etapa de Definição, iniciou-se a etapa "Medir" com a coleta de dados para refinar o problema. Os resultados medidos foram as diferentes visões dos participantes do processo por meio de um formulário online no qual as perguntas focam no problema e qual a lamentação de cada integrante do processo de aquisição de matéria prima. A partir da aplicação do formulário, fez-se a estratificação do problema como pode ser visto na Figura 6, isto é, observar o problema e elencar os fatores ligados à matéria prima que causam o atraso de entrega das peças automobilísticas. 


\section{empresa automobilística}

Figura 6: Estratificação dos dados coletados.

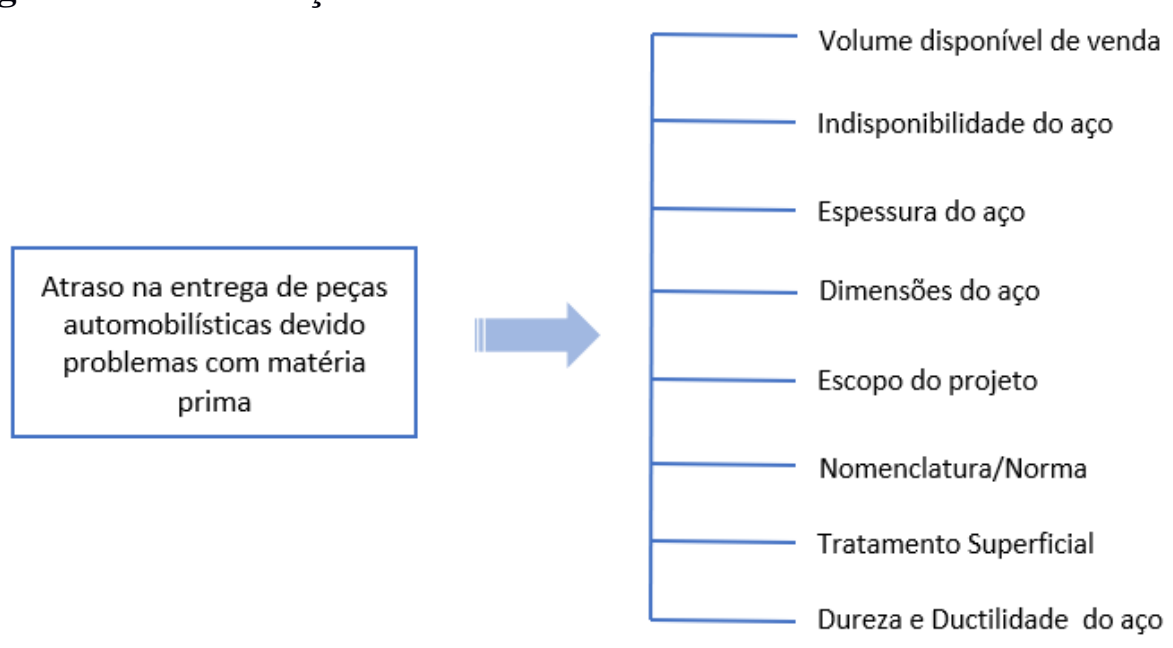

Fonte: Elaborada pelos autores, 2020.

De acordo com os dados coletados, os problemas de matéria prima recorrentes estão ligados com a compra desse aço e à qualidade do mesmo. Para se produzir uma peça protótipo a quantidade de aço necessária é menor quando comparada com a quantidade para construir uma peça de série. Assim, quando o fornecedor vai comprar o aço, o volume disponível de venda e os preços são altos (quando comparados com o custo e preço de venda da autopeça), o que se torna de certa forma inacessível essa compra.

Tratando-se das características específicas do aço, espessura e nobreza, por exemplo, determinadas espessuras e tipos de aço não são normalizados em grande escala de produção, o que dificulta a disponibilidade do mesmo. Já problemas ligados a propriedades do aço como por exemplo o tratamento superficial, dureza e ductilidade do material, interferem diretamente na qualidade exigida para se produzir a autopeça protótipo e quando a matéria prima não atende às especificações exigidas, gasta-se um tempo maior que o estipulado para compra e tem-se o atraso na entrega da peça.

Diante do elenco das possíveis causas do problema e com o objetivo de encontrar, os grandes responsáveis pelos efeitos indesejáveis no quesito entrega de peças automobilísticas desenvolveu-se um Diagrama de Pareto como mostrado na Figura 7. A amostra de dados tem origem em uma planilha disponibilizada pelo setor de Gestão de Compras da empresa que contém a relação de peças necessárias para um determinado projeto " $\mathrm{X}$ " do ano de 2018 e com as respectivas causas no atraso da entrega dessas peças mediante os fatores demonstrados na Estratificação dos dados coletados (Figura 6). A partir disso, foi possível verificar que $66,5 \%$ das razões que 


\section{Leandro Brant Vitoriano Vinte, Talyta Ferreira de Oliveira e}

Roberts Vinicius de Melo Reis

geram o problema, estão ligados à compra do aço como "Volume de Venda"; "Espessura"; "Dimensões" e "Indisponibilidade".

Figura 7: Diagrama de Pareto dos dados coletados.

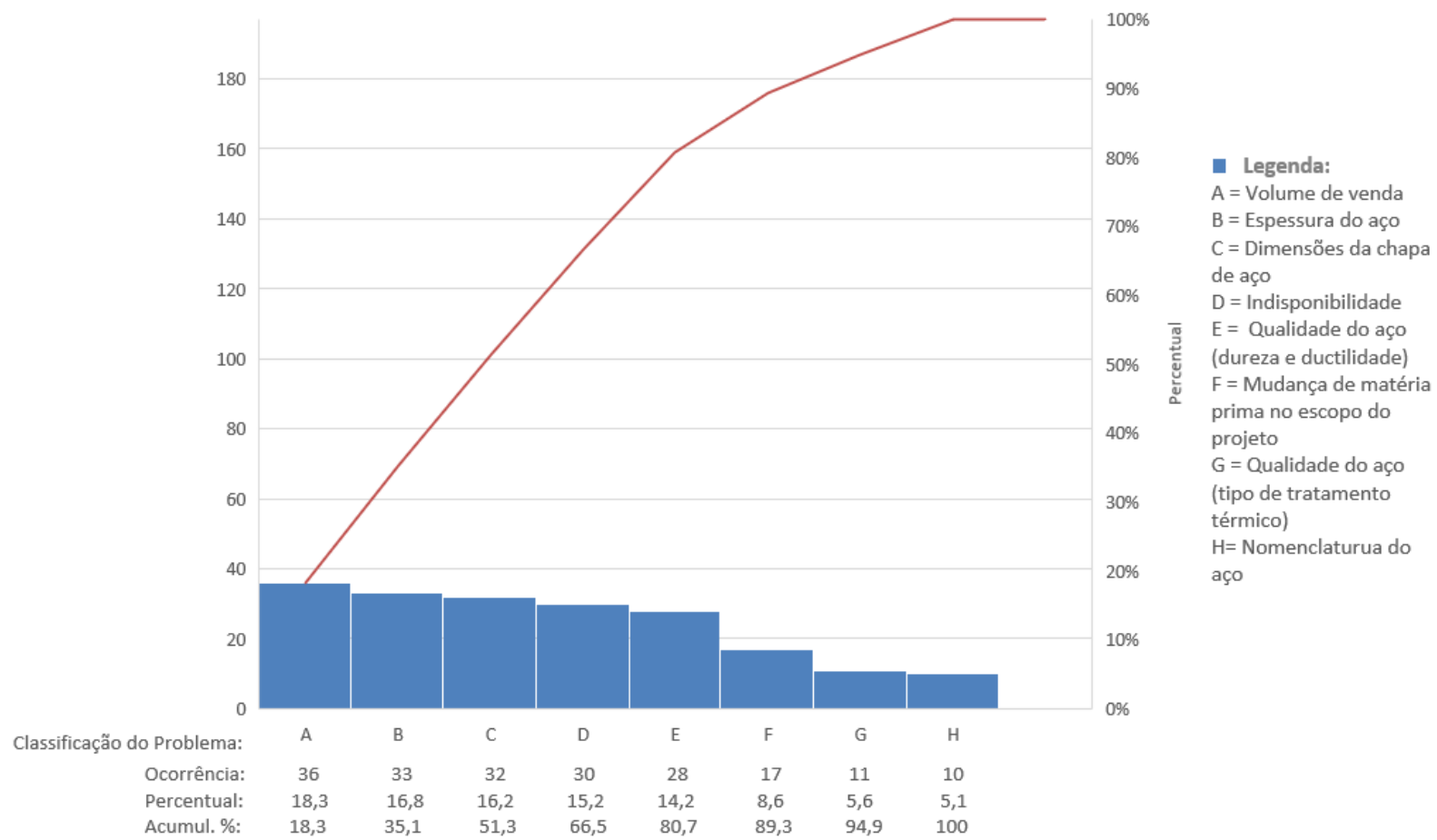

Fonte: Elaborada pelos autores, 2020.

\subsubsection{Etapa A (Analyze)}

Para analisar as fontes de variação fundamentais que contribuem para o atraso na entrega das autopeças, foram utilizadas ferramentas da qualidade tais como Fluxograma e Diagrama de Causa-Efeito. O Fluxograma disposto na Figura 8 promoveu um melhor entendimento do processo de aquisição de matéria prima para produção de autopeças e identificação de oportunidades para redução do tempo de atraso das peças do setor de protótipos.

Percebeu-se que muitas decisões são tomadas desde o estabelecimento de quais peças serão necessárias no projeto e seus respectivos materiais e que essas decisões afetam mais de um participante do processo.

Examinando o processo gerador do problema através do fluxograma demonstrado na Figura 9, percebe-se que a comunicação e a relações interpessoais também são fatores ligados aos problemas de compra da matéria prima, pois decisões de 


\section{empresa automobilística}

mudança de escopo do projeto são realizadas sem a ciência dos participantes, causando atraso na aquisição do aço e consequentemente na entrega da peça.

Figura 8: Fluxograma do processo de aquisição de matéria prima à montagem do carro.

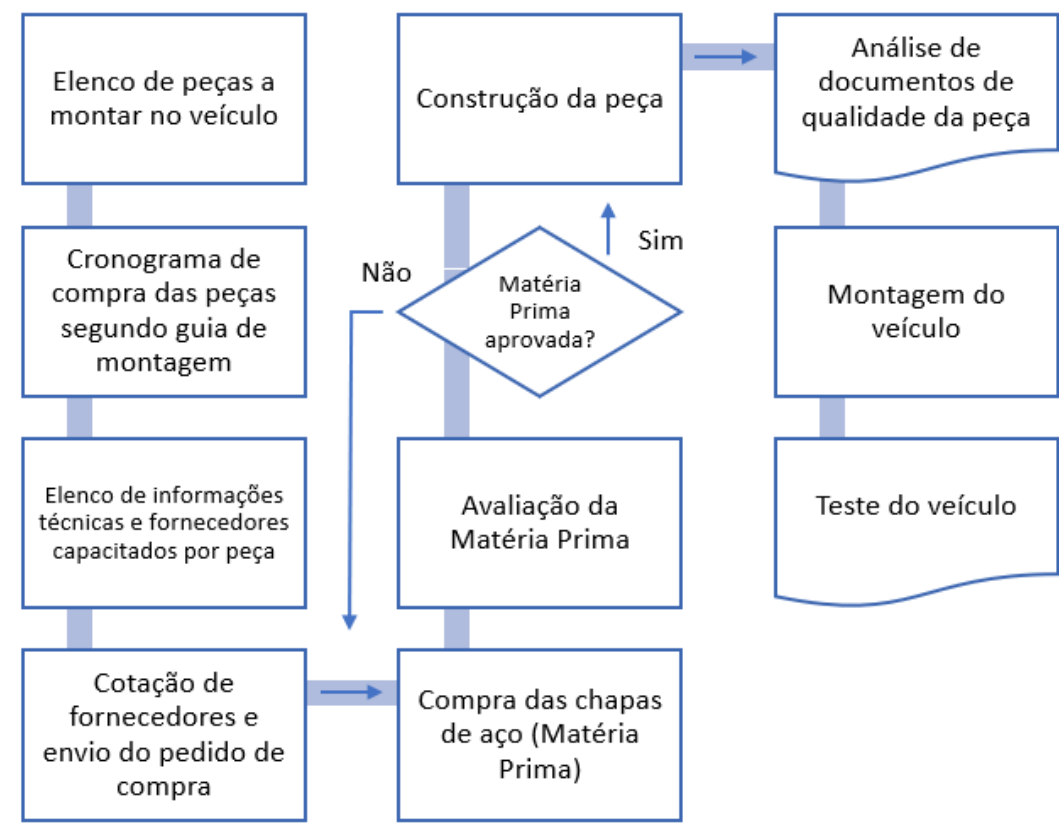

Fonte: Elaborada pelos autores, 2020.

Ademais, o Diagrama de Causa-Efeito é apresentado na Figura 9 e são demonstradas as causas da ineficiência do processo de aquisição de matéria prima e atraso na entrega das peças. Observa-se dificuldades de compra da matéria prima por parte do fornecedor, comunicação falha entre os participantes principalmente com as recorrentes mudanças de escopo do projeto e carência de qualidade do aço que será adquirido. 


\section{Leandro Brant Vitoriano Vinte, Talyta Ferreira de Oliveira e}

Roberts Vinicius de Melo Reis

Figura 9: Diagrama de Causa-Efeito do processo.

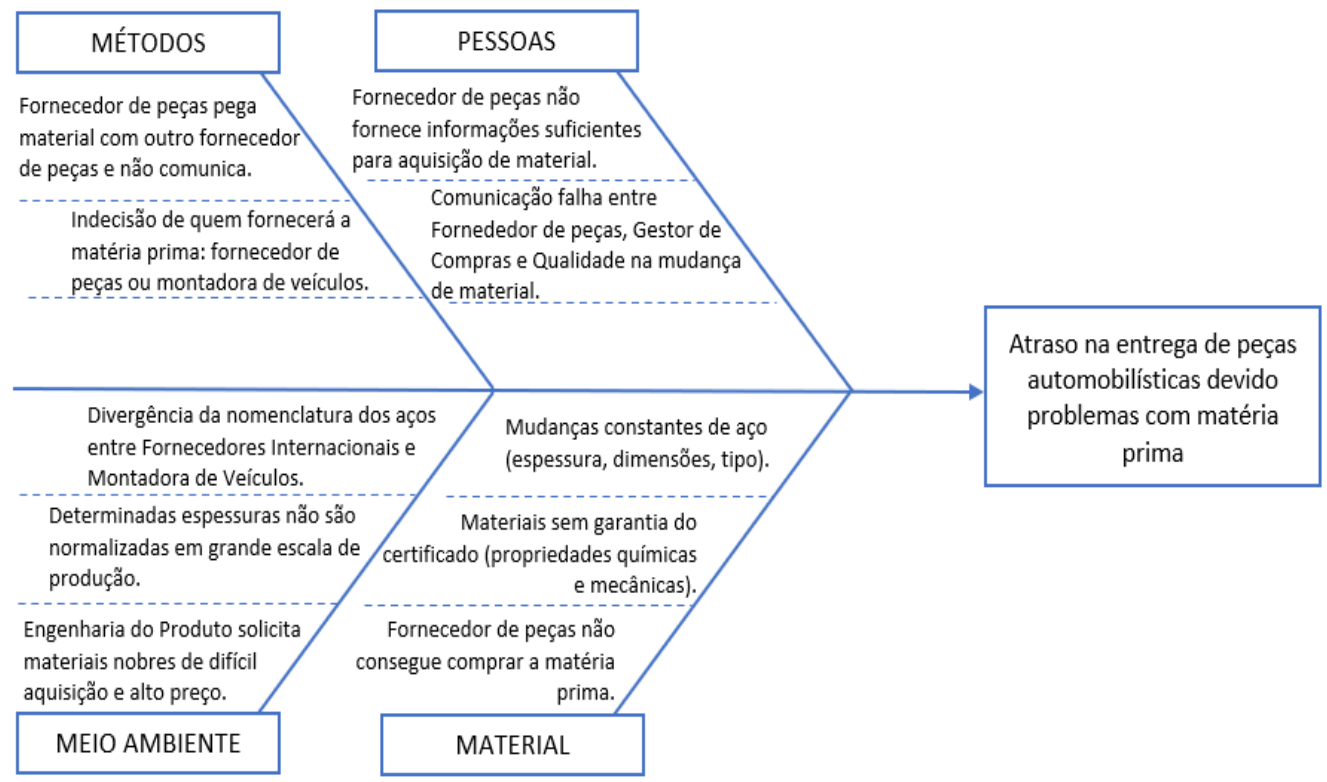

Fonte: Elaborada pelos autores, 2020.

\subsubsection{Etapa I (Improve)}

Diante do conhecimento das origens do problema e com o objetivo de levantar possíveis soluções, partindo da percepção que os stakeholders têm responsabilidade direta em minimizar as falhas do processo e melhorar a comunicação e relações interpessoais, utilizou-se a ferramenta Stakeholders Analysis (Figura 10) avaliando níveis atuais de comprometimento destes nas atividades e propondo níveis ideais para que as soluções prioritárias sejam implementadas com sucesso.

Figura 10: Stakeholders Analysis do projeto.

\begin{tabular}{|c|c|c|c|c|c|c|c|c|}
\hline & \multicolumn{8}{|c|}{ Stakeholder } \\
\hline $\begin{array}{c}\text { Nível de } \\
\text { Comprometimento }\end{array}$ & $\begin{array}{l}\text { Engenheiro } \\
\text { do Produto }\end{array}$ & $\begin{array}{l}\text { Gestor de } \\
\text { Projetos }\end{array}$ & $\begin{array}{l}\text { Gestor de } \\
\text { Compras }\end{array}$ & $\begin{array}{l}\text { Gestor da } \\
\text { Qualidade }\end{array}$ & $\begin{array}{l}\text { Comprador de } \\
\text { Peças }\end{array}$ & $\begin{array}{l}\text { Fornecedor de } \\
\text { Matéria Prima }\end{array}$ & $\begin{array}{c}\text { Engenheiro de } \\
\text { Materiais }\end{array}$ & $\begin{array}{c}\text { Fornecedor de } \\
\text { Peças }\end{array}$ \\
\hline Apoio Forte & & & $x_{1}$ & $x_{1}$ & & & & \\
\hline Apoio Moderado & $x$ & $x$ & 0 & 0 & & & & $x$ \\
\hline Apoio Fraco & 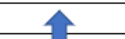 & $\sqrt{0}$ & & & & & & 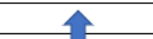 \\
\hline Neutro & & & & & & & $\Rightarrow$ & \\
\hline Oposição Fraca & 1 & & & & $0 \Longrightarrow \mathrm{x}$ & 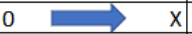 & & 1 \\
\hline Oposição Moderada & 0 & & & & & & & 0 \\
\hline Oposição Forte & & & & & & & & \\
\hline
\end{tabular}

Legenda: $\quad 0$ - Atual nível de comprometimento $\quad X$ - Nível de comprometimento necessário

Fonte: Elaborada pelos autores, 2020.

Examinando o nível de comprometimento dos gestores de compras e de qualidade, tem-se que o apoio deles é significativo aos fornecedores de matéria prima e de peça, pois com o poder de compra que eles possuem por representarem a empresa, 
Estudo sobre a aplicabilidade da metodologia dmaic no setor de protótipos de uma empresa automobilística

conseguem comprar volumes ideais de venda do aço com preços compatíveis ao mercado. Outro fator decisório na aquisição de matéria prima é quanto às características específicas do aço em relação ao que o projeto solicita. Pelo fato de a montadora de veículos possuir estoque com diversidade de aços quanto à espessura, dimensões e tipos, seu estoque é superior ao dos fornecedores, para a aquisição do que contribui para a aquisição do material que será utilizado na produção da peça em um curto prazo, não gerando atraso na entrega da peça.

Em situações em que o fornecedor tem dificuldades em adquirir o material conforme especificado, os gestores de compra e qualidade são os responsáveis por auxiliar os fornecedores no processo de compra do aço para não ocorrer atrasos na construção da peça e posteriormente na entrega da mesma. Diante desse cenário, propõe-se a disponibilização da matéria prima por parte do setor de protótipos da montadora de veículos com solicitações à equipe responsável pelo estoque de matéria prima e fornecedores de aço externos à fábrica, via e-mails formais contendo anexo uma tabela com as informações necessárias para obtenção do aço, conforme mostrado na Figura 11 .

Figura 11: Tabela de aquisição de matéria prima.

\begin{tabular}{|l|c|}
\hline Solicitante: & João Carneiro \\
\hline Setor: & Setor Protótipos \\
\hline Material: & LAC340Y480T \\
\hline Espessura: & $1,0 \mathrm{~mm}$ \\
\hline $\begin{array}{l}\text { Dimensões min. da } \\
\text { chapa de aço: }\end{array}$ & $500 \times 700$ \\
\hline $\begin{array}{l}\text { Quantidade de } \\
\text { chapas de aço: }\end{array}$ & 45 chapas \\
\hline Projeto: & 3890 \\
\hline Desenho das peças: & $\begin{array}{l}5864008 \\
5864009\end{array}$ \\
\hline
\end{tabular}

Fonte: Elaborada pelos autores, 2020.

Percebe-se que os agentes do processo que possuem oposição moderada são os que fornecem (Fornecedor de Peça) e recebem (Engenharia do Produto) o produto final, e a relação interpessoal deve ser harmônica e o contato deve ser direto, o que não acontece atualmente. Ocorrem situações em que o Engenheiro do Produto altera alguma das características do aço e os demais participantes do processo não ficam sabendo em 


\section{Leandro Brant Vitoriano Vinte, Talyta Ferreira de Oliveira e Roberts Vinicius de Melo Reis}

tempo hábil. Assim, propõe-se um formulário padrão (Figura 12) que requer a coleta de assinaturas digitais por parte da Engenharia do Produto em situações como a exposta anteriormente para que todos da cadeia tenham conhecimento das alterações necessárias no projeto.

Figura 12: Formulário de alteração de matéria prima.

\begin{tabular}{|c|c|c|c|}
\hline \multicolumn{4}{|c|}{ FORMULÁRIO DE REQUISIÇÃO DE MUDANÇA DE MATÉRIA PRIMA } \\
\hline Projeto: & $N^{\circ}$ Requisição: & Data Requisição: & 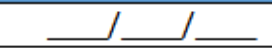 \\
\hline \multicolumn{2}{|l|}{ Requisitante: } & \multicolumn{2}{|l|}{ Setor: } \\
\hline Impacto: & ( ) Alto & ( ) Médio & ( ) Baixo \\
\hline \multicolumn{4}{|l|}{ Descrição da Mudança: } \\
\hline \multicolumn{4}{|l|}{ Motivo da Mudança: } \\
\hline \multicolumn{4}{|l|}{ Descrição do Impacto: } \\
\hline \multicolumn{4}{|l|}{ Escopo do Projeto: } \\
\hline \multicolumn{4}{|l|}{ Orçamento: } \\
\hline \multicolumn{4}{|l|}{ Cronograma: } \\
\hline \multicolumn{4}{|c|}{ Assinaturas: } \\
\hline Gestor de Projetos & \multicolumn{2}{|c|}{ Gestor de Qualidade } & Fornecedor de Peça \\
\hline Data: ___ _ _ & \multicolumn{2}{|c|}{ Data: _ـ_ _ } & Data: ___ \\
\hline
\end{tabular}

Fonte: Elaborada pelos autores, 2020.

Tendo como base as soluções propostas, elaborou-se a ferramenta 5W1H (figura 13), definindo e agrupando as informações necessárias para colocar o plano de ação em prática. Como demonstrado no $5 \mathrm{~W} 1 \mathrm{H}$, os responsáveis pela execução do plano delimitaram-se aos funcionários da montadora de veículos, pelo fato das pessoas estarem dividindo o mesmo local de trabalho a comunicação é mais assertiva e a adaptação por mudanças no processo será mais eficaz e ágil, pois elas vivem sob a mesma cultura organizacional. 
Figura 13: 5W1H: plano de ação.

\begin{tabular}{|c|c|c|c|c|c|}
\hline WHAT & WHO & WHEN & WHERE & WHY & HOW \\
\hline $\begin{array}{l}\text { - Padronizara a } \\
\text { aquisição de } \\
\text { material } \\
\text { - Melhorar a } \\
\text { comunicação } \\
\text { entre os } \\
\text { stakeholders }\end{array}$ & $\begin{array}{l}\text { - Gestor de } \\
\text { Compras e } \\
\text { Gestor de } \\
\text { Qualidade } \\
\text { - Engenheiro do } \\
\text { Produto }\end{array}$ & $\begin{array}{l}\text { - Agosto/2020 } \\
\text { - Agosto/2020 }\end{array}$ & $\begin{array}{l}\text { - Estoque de } \\
\text { aço da } \\
\text { montadora de } \\
\text { veículos. } \\
\text { - Via formulário } \\
\text { digital com } \\
\text { assinaturas } \\
\text { digitais. } \\
\text { Sistema } \\
\text { DocuSign. }\end{array}$ & $\begin{array}{l}\text { - Reduzir } \\
\text { problemas de } \\
\text { compra e } \\
\text { qualdiade da } \\
\text { matéria prima } \\
\text { para não } \\
\text { causar atraso } \\
\text { na entrega da } \\
\text { peça. } \\
\text { - Melhorar a } \\
\text { comunicação } \\
\text { entre os } \\
\text { stakeholders }\end{array}$ & $\begin{array}{l}\text { - Montadora de } \\
\text { veículos } \\
\text { fornecerá o } \\
\text { material aos } \\
\text { fornecedores. } \\
\text { - Toda mudança } \\
\text { no projeto } \\
\text { deverá ser } \\
\text { assinada por } \\
\text { todos os } \\
\text { participantes } \\
\text { do processo } \\
\text { para ciência } \\
\text { das } \\
\text { alteraç̃̃es. }\end{array}$ \\
\hline
\end{tabular}

Fonte: Elaborada pelos autores, 2020.

\subsubsection{Etapa C (Control)}

No intuito de confirmar o alcance de sucesso do plano de ação e garantir que as melhorias obtidas não se percam, é necessário estabelecer métodos de controle ao processo. Para o projeto em questão, sugere-se que ocorra mensalmente a medição dos percentuais de peças que tiveram atraso na entrega de forma comparativa com os meses anteriores por meio do Diagrama de Pareto. Existindo aumento desses percentuais, propõe-se que os gestores de compra e de qualidade façam visitas semanais aos fornecedores para acompanhar o processo produtivo das peças e minimizar danos.

Ademais sugere-se reuniões mensais de acompanhamento organizadas pelo gestor de projetos com um representante de cada agente do processo. Essas reuniões têm como objetivo apresentar os resultados mensais comparativos do Diagrama de Pareto, verificar o cumprimento do cronograma e atualizar a equipe em caso de mudanças de escopo, obtendo-se uma visão geral do projeto.

As sugestões de boas práticas que possivelmente podem ser feitas na aplicação do método DMAIC, não foram colocadas em práticas pelo fato da cultura organizacional da empresa. Quaisquer mudanças de atividades no setor de protótipos devem ser aprovadas pela diretoria para analisar se o que foi proposto irá ser padronizado ou não. 


\section{CONSIDERAÇÕES FINAIS}

O presente estudo propôs a análise da aplicabilidade da metodologia DMAIC para melhoria do processo de aquisição de matéria prima na construção de peças automobilísticas. Tais peças são utilizadas para montagem de veículos no setor de protótipos de uma fabricante localizada na região metropolitana de Belo Horizonte.

Para alcançar o objetivo geral foram estabelecidos objetivos específicos, tais como determinar as ferramentas da qualidade necessárias para levantar as reais causas do atraso na entrega das autopeças e propor um plano de ação que reduza o atraso de entrega das peças.

A partir da entrevista estruturada pôde-se decidir quais ferramentas da qualidade seriam mais adequadas para que método DMAIC tivesse sucesso na aplicação. Assim, atingiu-se o objetivo principal deste trabalho, obtendo êxito na análise da aplicabilidade de uma metodologia que relacionasse o projeto, fabricação das autopeças, qualidade final, a entrega do produto e a satisfação dos consumidores. Esses feitos que apoiam o projeto, fundamentam o Seis Sigma ao qual a metodologia DMAIC está integrada.

O estudo de caso revelou que a padronização do processo é uma proposta de melhoria para reduzir o atraso de entrega das autopeças no setor de protótipos da montadora. Sugeriu-se que o plano de melhoria deveria partir da disponibilidade da matéria prima por parte da montadora para construir as autopeças, além da utilização de tabelas e formulários específicos para tornar a comunicação entre as partes interessadas mais eficaz.

A empresa em questão possui uma cultura empresarial sólida na qual a existência de uma hierarquia de aprovação se faz presente em situações de mudança de processos. Diante dessa situação, o objetivo de melhorar o processo de aquisição de matéria prima por meio da padronização do mesmo se deu como parcial, pois o plano de ação sugerido ainda não foi implementado no setor de protótipos, aguardando aprovação da diretoria.

Conclui-se que na etapa de prototipagem de projetos de uma empresa automobilística, foi possível perceber que a aplicação da metodologia DMAIC possibilita um bom direcionamento das causas do problema de atraso de entrega das 
peças e assim propor ações de melhoria para que o tempo de atraso reduza-se para as fases de projetos atuais e futuros.

\section{REFERÊNCIAS}

ALVES,José Leonardo Liborio.; XAVIER, Amanda da Silva.; SILVA, Andersson Alves da.; ALBUQUERQUE, Ramses Moreira de.; ALENCAR, Tharsis Cidalia de Sa Barreto Diaz. Seis Sigma e sua aplicabilidade como ferramenta de qualidade em processos industriais. XXXVI Encontro Nacional De Engenharia De Produção, 2016. Disponível em: <http://www.abepro.org.br/biblioteca/TN_STO_226_316_30423.pdf> Acesso em: 17 set. 2019.

BARROS, Elsimar; BONAFINI, Fernanda Cesar. Ferramentas da Qualidade. Pearson Education Brasil, São Paulo, 2015.

BESANKO, D.; DRANOVE, D.; SHANLEY, M.; SCHAEFER, S. A Economia da Estratégia. 5 ed. Porto Alegre: Bookman, 2012.

CAMPOS, Vicente Falconi. Gerenciamento da rotina do trabalho do dia-a-dia. 9. ed. Belo Horizonte: Falconi, 2013.

CARPINETTI, Luiz Cesar Ribeiro. Gestão da Qualidade: conceitos e técnicas. 3 ed. São Paulo: Atlas, 2016.

CILO, Nelson. As Reformas Vão Tornar O País Mais Competitivo - Estado de Minas - Belo Horizonte, 03 de setembro de 2019, atualizado às 07:47.

Disponível em:<https://www.em.com.br/app/noticia/economia/2019/09/03/internas_eco nomia, 1081959/as-reformas-vao-tornar-o-pais-mais-competitivo.shtml> Acesso em: 30 set. 2019.

CORTEZ, Pedro Roberto Lemos.; BACHOUR, Marina Coelho. PEREIRA, Maria Cecília.; DIAS, Ana Valéria Carneiro.; BAGNO, Raoni Barros. Análise Das Relações Entre O Processo De Inovação Na Engenharia De Produto E As Ferramentas Do WCM: Estudo De Caso Em Uma Empresa Do Setor Automobilístico.

XXXVI Encontro Nacional De Engenharia De Produção, 2010. Disponível em: <http://www.abepro.org.br/biblioteca/enegep2010_tn_sto_131_838_16445.pdf> Acesso em: 17 set. 2019.

COUTINHO, Fagner Melo José.; AQUINO, Joás Tomaz de. Os 5s Como Diferencial Competitivo Para o Sistema de Gestão da Qualidade: Estudo de Caso de Uma Empresa de Aços Longos. Revista Gestão.Org, v. 13, n. 2, 2015. p 176-186. Disponível

em: 


\section{Leandro Brant Vitoriano Vinte, Talyta Ferreira de Oliveira e \\ Roberts Vinicius de Melo Reis}

<https://periodicos.ufpe.br/revistas/gestaoorg/article/view/22077/18464> Acesso em: 20 nov. 2019.

CRESWELL, John W. Investigação Qualitativa e Projeto de Pesquisa: Escolhendo entre Cinco Abordagens. 3 ed. Porto Alegre: Penso, 2014.

DEUS, André Diehl de.; VACCARO, Guilherme Luís Roehe. Uma Abordagem Para Implementação De Qualidade Assegurada No Fornecimento, Baseada Em Análise De Capacidade: Um Estudo De Caso Em Uma Empresa Do Setor Automotivo.

Revista Produção Online, v. 9, n. 4, 2009.

Disponível em: <https://www.producaoonline.org.br/rpo/article/view/238/540> Acesso em: 20 nov. 2019.

FALCONI, Vicente. Gerenciamento da rotina. 9 ed. Nova Lima: FALCONI Editora, 2013.

FCA- Fiat Chrysler Automobiles. Latam. [S.l], 2020. Página inicial. Disponível em: $<$ https://www.fcagroup.com/en-US/group/regions/Pages/latam_pt.aspx>. Acesso em: Acesso em: 17 set. 2019.

FERNANDES, Renan Maia; REIS Augusto da Cunha; SENNA, Pedro. Utilização Da Metodologia Dmaic Em Um Hospital Da Rede Pública Federal Com Foco Em Melhoria Da Previsão De Demanda Por Consultas.

Revista Brasileira de Gestão e Inovação, v.5, n.2, Janeiro/Abril, 2018. Disponível em: <http://www.ucs.br/etc/revistas/index.php/RBGI/article/view/5186> Acesso em: 02 mar. 2020.

FLORES, Renan Ednan.; FARACO, Newton Nauro Tasso.; BONDE, Danielle. Proposta De Metodologia Para Construção Da Ferramenta De Análise De Falhas No Contexto Do WCM (World Class Manufacturing).

XXXVI Encontro Nacional De Engenharia De Produção, 2016. Disponível em: <http://www.abepro.org.br/biblioteca/TN_STP_226_321_28729.pdf> Acesso em: 17 set. 2019.

LINO, Luana Aparecida. Aplicação da ferramenta dmaic para um projeto de melhoria em uma empresa de mineração no sul de minas.

Pontifícia Universidade Católica de Minas Gerais, 2018.

Disponível

em:

<http://bib.pucminas.br:8080/pergamumweb/vinculos/00002c/00002ccf.pdf> Acesso em: 17 set. 2019.

PANDE, S.; NEUMAN, Robert P.; CAVANAGH,Roland R. Estratégia Seis Sigma: como a GE a Motorola e outras grandes empresas estão aguçando seu desempenho. Rio de Janeiro: Qualitymark Ed, 2004. 
Estudo sobre a aplicabilidade da metodologia dmaic no setor de protótipos de uma empresa automobilística

PINTO, Silvia Helena Boarin.; CARVALHO, Marly Monteiro de.; HOO, Linda Lee. Programa Seis Sigma: Aspectos Sinérgicos Com Outras Abordagens De Gerenciamento Da Qualidade.

Revista Produção Online, v. 9, n. 1, 2009.

Disponível em: <https://www.producaoonline.org.br/rpo/article/view/203/317> Acesso em: 20 nov. 2019.

ROTONDARO, Roberto G. Seis Sigma: estratégia gerencial para a melhoria de processos, produtos e serviços. São Paulo: Atlas, 2002.

SLACK, Nigel. Administração da Produção. São Paulo: Editora Atlas S.A., 1999.

TUBINO, Dalvino Ferrari. Manufatura enxuta como estratégia de produção: a chave para produtividade industrial. São Paulo, Editora Atlas, 2015.

TURRIONI, João Batista.; MELLO, Carlos Henrique Pereira. Metodologia de Pesquisa em Engenharia de Produção. Unifei, 2012. Disponível em: $<$ http://www.marco.eng.br/adm-organizacao-

I/Apostila_Metodologia_Completa_2012_\%20UNIFEI.pdf> Acesso em: 20 nov. 2019.

WERKEMA, Cristina. As Ferramentas da qualidade no gerenciamento de processos. Rio de Janeiro: Elsevier Editora Ltda, 2013.

WERKEMA, Cristina. Criando a cultura Lean Seis Sigma. 3 ed. Rio de Janeiro: Elsevier Editora Ltda, 2012.

WERKEMA, Cristina. Métodos PDCA e DMAIC e suas ferramentas analíticas. 3 ed. Rio de Janeiro: Elsevier Editora Ltda, 2012.

YIN, Robert K. Estudo de caso: planejamento e métodos. 5 ed. Porto Alegre: Bookman, 2015.

YIN, Robert K. Pesquisa qualitativa do início ao fim. Porto Alegre: Penso, 2014. 


\section{Leandro Brant Vitoriano Vinte, Talyta Ferreira de Oliveira e}

Roberts Vinicius de Melo Reis

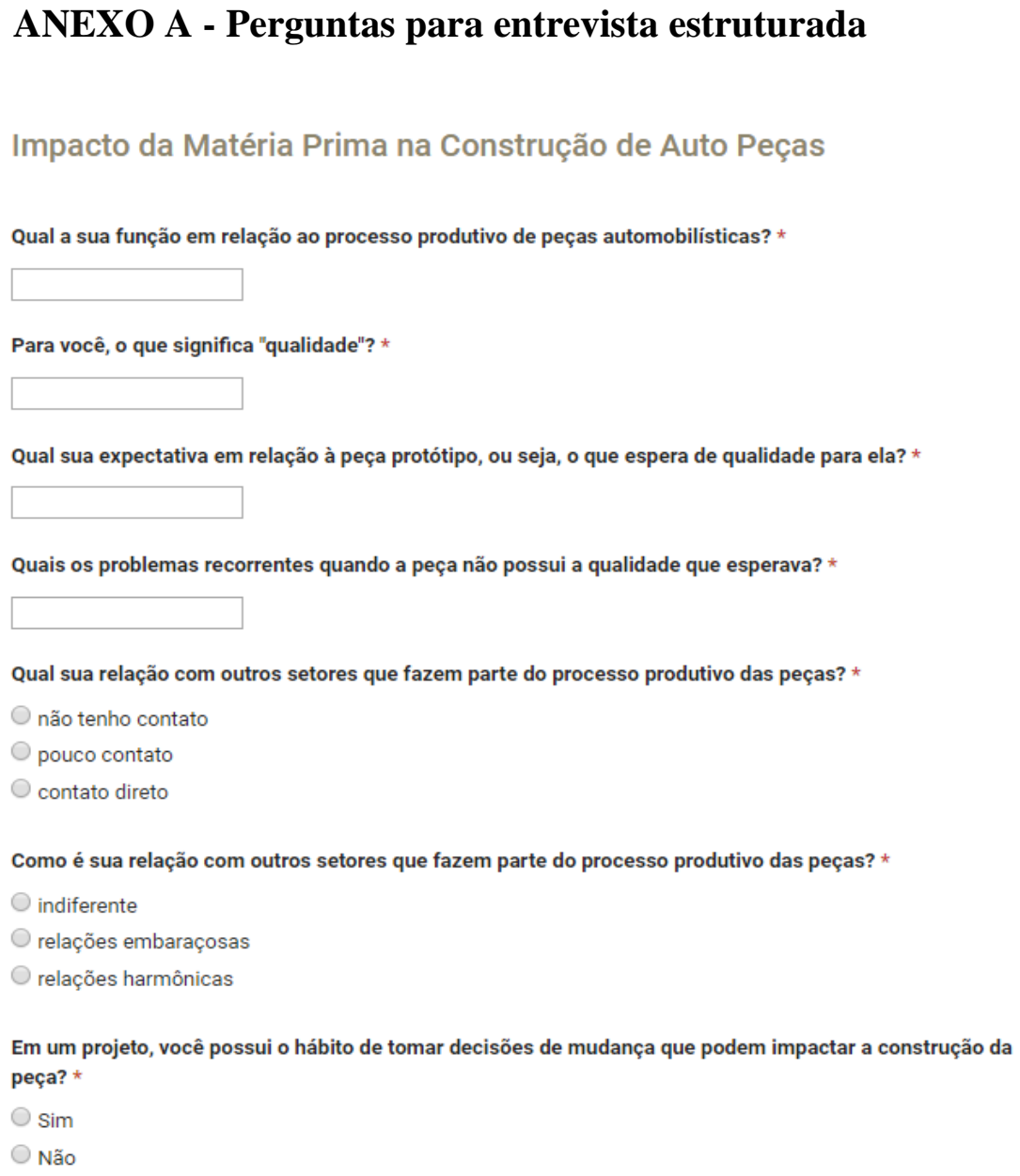

Quais fatores geralmente levam à mudança? *

Qual sua opinião sobre a importância da matéria prima no processo produtivo das peças? *

Quais os problemas ligados à matéria prima das peças, que você enfrenta em um projeto? *

Em decorrência de dúvidas e/ou dificuldade em alguma atividade, você recorre à algum participante do processo solicitando ajuda? *

Sim

Não

Quais as pessoas que geralmente solicita ajuda? *

Enviar 
Estudo sobre a aplicabilidade da metodologia dmaic no setor de protótipos de uma empresa automobilística

Fonte: Google Forms Online, (2019). 